\title{
Cell Wall Assembly in Bacillus subtilis: Partial Conservation of Polar Wall Material and the Effect of Growth Conditions on the Pattern of Incorporation of New Material at the Polar Caps
}

\author{
By A. J. CLARKE-STURMAN,${ }^{1}+$ A. R. ARCHIBALD,${ }^{1}$ I. C. HANCOCK, ${ }^{1}$ \\ C. R. HAR WOOD,${ }^{*}$ T. MERAD ${ }^{1}$ AND J. A. HOBOT ${ }^{2}$ \\ ${ }^{1}$ The Microbial Technology Group, Department of Microbiology, \\ University of Newcastle upon Tyne, Framlington Place, Newcastle upon Tyne NE2 4HH, UK \\ ${ }^{2}$ EM Unit, University of Wales College of Medicine, Heath Park, Cardiff CF4 4XN, UK
}

(Received 1 August 1988; revised 4 November 1988; accepted 15 November 1988)

\begin{abstract}
The use of phage SP50 as marker for cell wall containing teichoic acid in Bacillus subtilis showed clear differences in the rates at which new wall material becomes exposed at polar and cylindrical regions of the wall, though the poles were not completely conserved. Following transition from phosphate limitation to conditions that permitted synthesis of teichoic acid, old polar caps fairly rapidly incorporated enough teichoic acid to permit phage binding. Electron microscopy suggested that the new receptor material spread towards the tip of the pole from cylindrical wall so that phages bound to an increasing proportion of the pole area until only the tip lacked receptor. Eventually, receptor was present over the whole polar surface. Direct electron microscopic staining of bacteria collected during transitions between magnesium and phosphorus limitations showed that new material was incorporated at the inner surface of polar wall and later became exposed at the outer surface by removal of overlying older wall. The apparent partial conservation of the pole reflected a slower degradation of the overlying outer wall at the pole than at the cylindrical surface, the rate being graded towards the tip of the pole. The relative proportions of the new wall material incorporated into polar and cylindrical regions differed in bacteria undergoing transitions that were accompanied by upshift or downshift in growth rate. These differences can be explained on the basis that growth rate affected the rate of synthesis of cylindrical but not septal wall.
\end{abstract}

\section{INTRODUCTION}

Cell wall material is present in Bacillus subtilis in the cylindrical region of the wall, in septa and in polar caps. Material forming the polar cap differs in shape from cylindrical wall and is assembled from an annular growth zone distinct from the sites of cylindrical wall assembly (Anderson et al., 1978; Mobley et al., 1984). It also differs metabolically from cylindrical wall in that material is conserved at the poles to a greater extent than in the cylinder. This conservation is shown most clearly by experiments in which $B$. subtilis is grown so that old and new wall differ in the nature of the anionic polymer, teichoic acid (TA) or teichuronic acid (TU), linked to the peptidoglycan. Phage SP50 binds specifically to bacteria that contain TA but not to phosphatelimited bacteria, in which TA is replaced by TU. Following transition to phosphate limitation the bacteria retain the ability to bind TA-specific phages to old poles for up to six generation times after synthesis of TA has ceased, although cylindrical wall loses the ability to bind phages

† Present address: Sittingbourne Research Centre, Sittingbourne, Kent ME9 8AG, UK.

Abbreviations: TA, teichoic acid; TU, teichuronic acid; TA or TU walls, cell wall material containing predominantly TA or TU as the anionic polymer, respectively. 
within two generation times (Archibald, 1976; Archibald \& Coapes, 1976; Sturman \& Archibald 1978). Similar results have been obtained using concanavalin A as a marker for glucosylated TA (Mobley et al., 1984). Autoradiographic studies of bacteria containing radiolabelled peptidoglycan have also shown preferential conservation of label at the poles (Mobley et al., 1984). It seems likely that images obtained in studies using fluorescent antibody as a marker for wall growth in Bacillus licheniformis (Hughes \& Stokes, 1971) and in Bacillus megaterium and Bacillus cereus (Chung et al., 1964) also reflect the preferential conservation of polar wall material, and not a zonal growth pattern as was originally proposed.

Evidence on the metabolic activity at the poles is contradictory. In some experiments rapid turnover of poles has been observed (Fan et al., 1974) but studies on the kinetics of cell wall turnover (Doyle et al., 1980; Clarke-Sturman \& Archibald, 1982) have shown the presence of a conserved, or only slowly turned over, wall component that may be the material forming the pole. Polar material shows resistance to lytic enzymes under some conditions (Fan \& Beckman, 1973) and this may explain the observed conservation of poles (Sturman \& Archibald, 1978; Kirchner et al., 1984). Koch \& Doyle (1986) have suggested that poles may be less stressed than cylindrical wall and for this reason more resistant to autolytic enzymes. Sturman and Archibald (1978) have suggested that polar wall may not be in contact with autolysin in growing bacteria.

Conserved poles form an important element in the proposal (Koch, 1983; Koch \& Doyle, 1986) that elongation of the cylindrical wall in bacilli takes place by stretching (Fan et al., 1975) and cutting of wall material supported by the two rigid poles. However, the poles may not be completely conserved since it is known that old poles containing TU do develop an ability to bind phage SP50 when the bacteria are grown under conditions where TA is synthesized (Sturman \& Archibald, 1978).

This paper describes a more detailed study of the metabolic status of polar caps in B. subtilis undergoing transitions between different growth conditions.

\section{METHODS}

Organisms. B. subtilis strains $\mathrm{CH} 724$ and $\mathrm{CH} 725$, prototrophic derivatives of strains 168 and $\mathrm{W} 23$, respectively, were from our laboratory collection.

Culture of bacteria. Maintenance and batch culture of B. subtilis 168 were as described in the accompanying paper (Merad et al., 1989). B. subtilis W23 was grown in chemostat culture as previously described (Sturman \& Archibald, 1978) at $37^{\circ} \mathrm{C}, \mathrm{pH} 7.0$ and $D=0.2 \mathrm{~h}^{-1}$. Steady state was established under conditions of phosphate limitation using medium that contained $1.44 \mathrm{~mm}$ inorganic phosphate and $4.3 \mathrm{~mm}-\mathrm{K}^{+}$, and for transition to potassium limitation the new inflowing medium contained $4.81 \mathrm{~mm}$ inorganic phosphate and $3.02 \mathrm{~mm}-\mathrm{K}^{+}$. Samples were collected by centrifugation at $2{ }^{\circ} \mathrm{C}$ following changeover; the bacteria were then washed in distilled water and freeze-dried.

Electron microscopy. B. subtilis 168 was examined in thin section by electron microscopy as described in the accompanying paper (Merad et al., 1989). For phage-binding studies B. subtilis W23 was incubated with phage SP50, fixed and prepared for electron microscopy as previously described (Archibald \& Coapes, 1976). Grids were examined in an AEI EM6 electron microscope as previously reported (Sturman \& Archibald, 1978).

\section{RESULTS AND DISCUSSION}

Samples of bacteria removed from a phosphate-limited chemostat culture of B. subtilis W23 had TU in their walls and showed little or no ability to bind phage SP50. Electron microscopic examination showed that of the 1980 poles examined, $99 \%$ bound no phage particles. When the medium is changed to one in which potassium is the limiting nutrient, the bacteria synthesize wall TA. After a delay during which the new, TA-containing, wall material moves from the inner to the outer surface of the wall cylinder, the bacteria develop the ability to bind phage particles along their cylindrical length but not at polar caps formed before changeover (Anderson et al., 1978). The proportion of poles that bound phage determined for samples taken at intervals after changeover (Fig. 1), increased rapidly so that of the 1830 poles examined at 1.8 generation times after changeover only 9 (i.e. $0.5 \%$ ) did not bind phage. If all new poles formed after changeover contained enough TA to permit phage binding, but the old poles were fully conserved and did not incorporate TA, the proportion of poles that remain unable to bind phage 


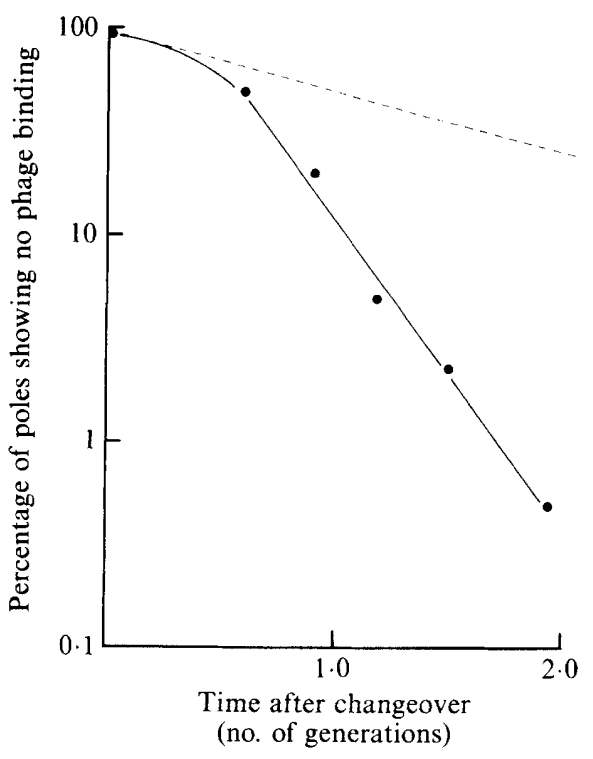

Fig. 1. Phage binding to polar caps of bacteria collected during changeover from phosphate to potassium limitation. $B$. subtilis W23 was grown at $D=0.21 \mathrm{~h}^{-1}$. The broken line shows the theoretical diminution in the proportion of polar caps that cannot bind phages calculated from the assumption that old caps are fully conserved and incorporate no new wall material and that the receptor is incorporated into new poles immediately after changeover. Conditions for phosphate limitation and changeover to potassium limitation were described previously (Sturman \& Archibald, 1978).

would halve after each generation time. The values would be $50 \%$ after one generation time, $25 \%$ after two generation times, and so on as shown by the broken line in Fig. 1 . The values obtained in the experiment (Fig. 1) clearly show that the poles are not conserved but rapidly acquire enough TA to permit phage binding. The number of 'conserved' poles seen after 1.8 generations $(0.5 \%)$ is so much lower than would be expected if the poles were fully conserved $(29 \%)$ that we can also rule out the possibility that new material is incorporated into the poles for only a short period after their formation (e.g. as part of a maturation process). Since the theoretical proportion of 'conserved' poles would fall by only half for each generation time that such maturation proceeds, maturation for one or for two generation times following division would be expected to reduce the number of 'conserved' poles seen here at 1.8 generation times after changeover to $14.5 \%$ or $7.25 \%$ respectively, values that are still greatly in excess of that $(0.5 \%)$ found. It follows that receptor TA must be incorporated into poles that are formed two and more generation times before changeover.

Development of phage-binding properties may be progressive, starting from the region near the junction with cylindrical wall (Fig. 2). Bacteria collected 0.6 generation times after changeover bound phage to the cylinder but not the poles which were essentially free of phage (Fig. $2 a$ ). Clear polar caps were also seen in many of the bacteria collected at 0.9 generation times after changeover (Fig. $2 b$ ) but other bacteria in these samples bound phage to parts of the pole adjacent to cylindrical wall (Fig. $2 c, d$ ) so that only the tip was uncovered. Bacteria in which one pole was less densely covered than the other (Fig. $2 e$ ) and bacteria in which both poles were uniformly covered with phage (Fig. $2 f$ ) were also found in this sample.

The micrographs obtained with phage reflect the composition of only the outermost layers of the wall and therefore do not permit distinction between spreading of new receptor material into the poles from adjacent cylindrical wall (Sturman \& Archibald, 1978), slower inside-to-outside growth at the poles, or slower removal of the outermost wall layer at the poles. However, the differential electron microscopic staining procedure described in the accompanying paper 
(a)
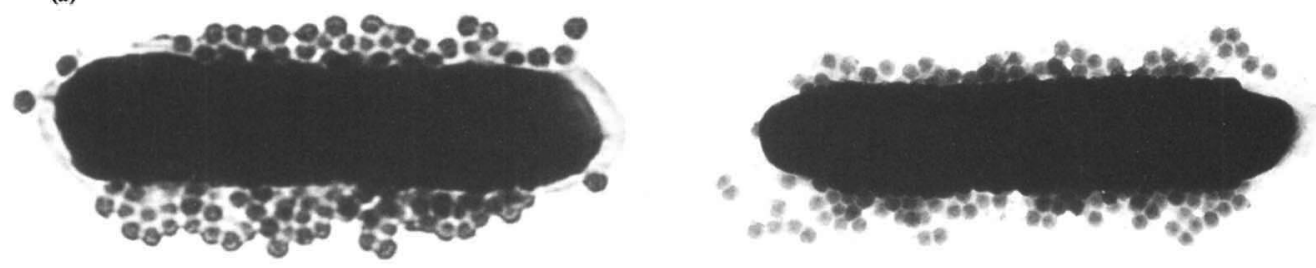

(c)
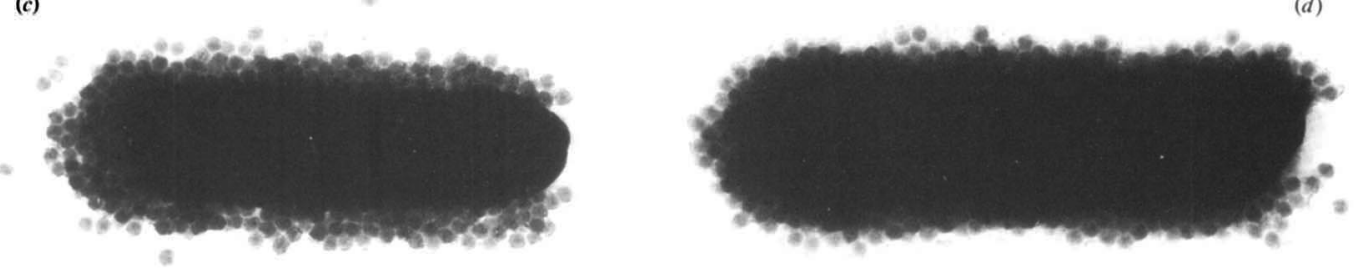

(e)
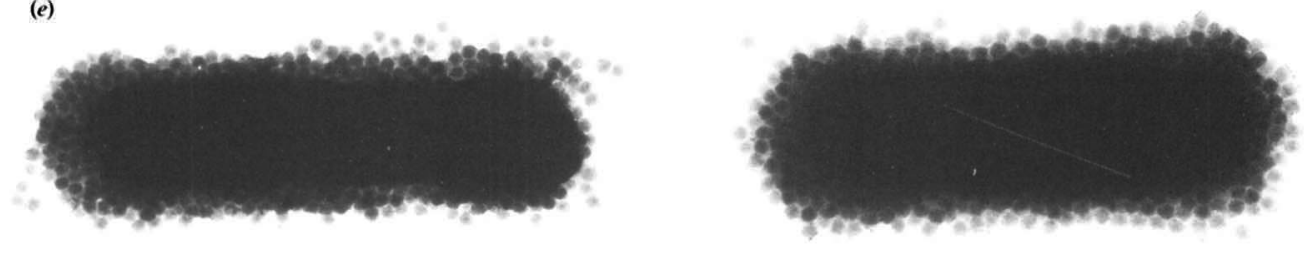

$(f)$

Fig. 2. Electron microscopy of phage binding. Phage SP50 binding to B. subtilis W23 was examined in samples taken $(a) 0.6$ and $(b-f) 0.9$ generation times after changeover to potassium limitation. Bacteria were incubated with phage, fixed, prepared and examined by electron microscopy as previously described (Archibald \& Coapes, 1976). Bar marker, 0.25 $\mu \mathrm{m}$.

(Merad et al., 1989) allows distinction between wall materials containing TA and TU, and shows their distribution within the wall. The pattern of incorporation seen at the poles depended on the growth conditions.

In experiments with $B$. subtilis 168 , changeover from phosphate to magnesium limitation resulted first (Fig. $3 a$ ) in a uniform increase in the electron opacity of the 'A' layer of Merad et al. (1989) beneath both polar and cylindrical wall regions. Following this, visible amounts of densely staining material containing TA were incorporated uniformly into the cylindrical wall but not initially into the old poles (Fig. $3 b$ ). These poles did incorporate densely staining material, but more slowly. This may take place by a graded incorporation of new material into the pole by spreading from its initial location in the adjacent cylindrical wall (Fig. $3 c$ ) as well as by an inside-to-outside process whose rate is lower than that of cylindrical wall synthesis but which ultimately leads to the incorporation of a uniformly thick layer at the inner region of the polar wall (Fig. $3 d, e$ ).

Examination of bacteria collected during transition from magnesium to phosphate limitation suggested a more equal rate of incorporation of new wall material into the inner surface of both 

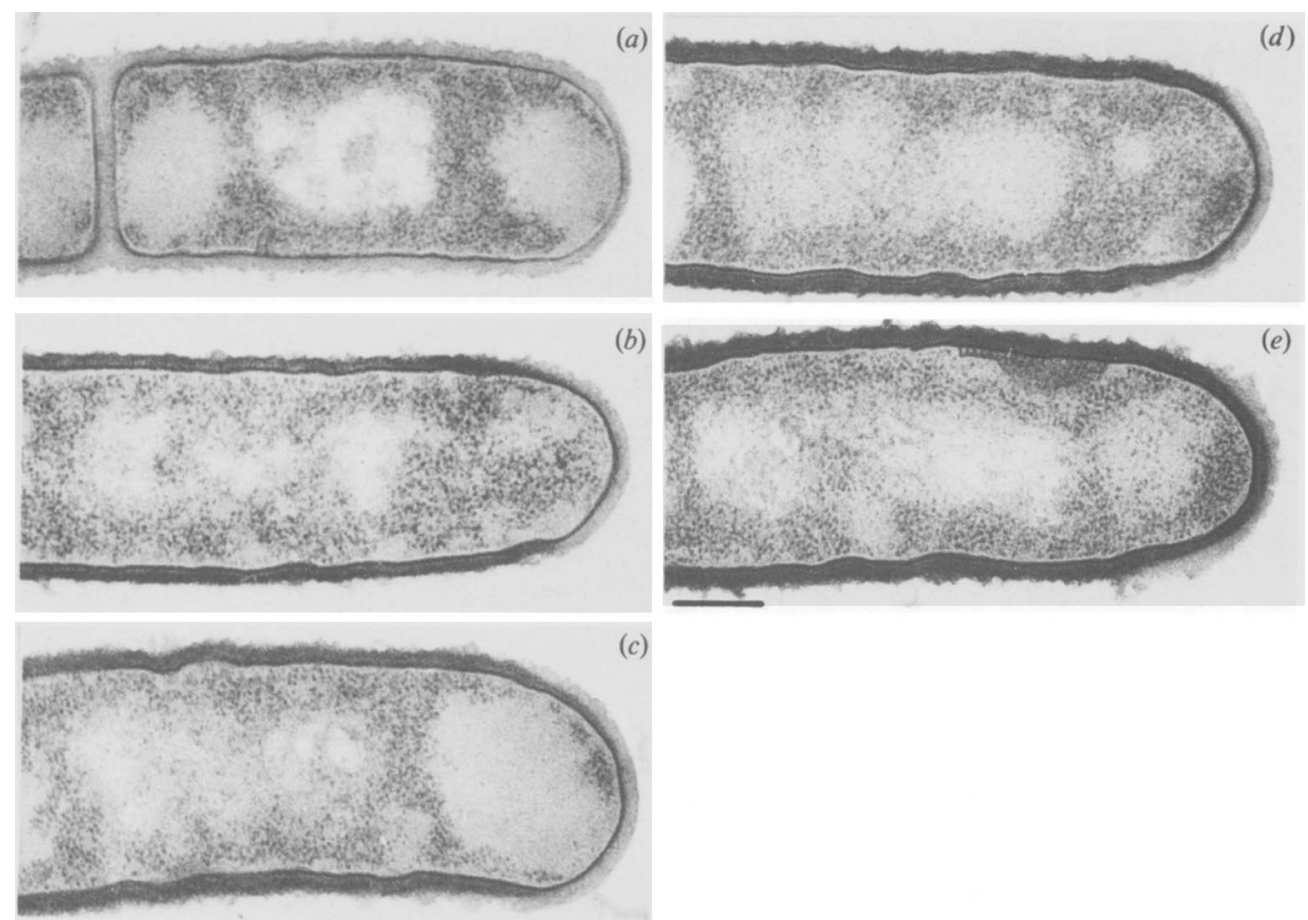

(c)

Fig. 3. Deposition of new cell envelope material in B. subtilis 168 during transition from phosphate to magnesium limitation. Bacteria were equilibrated under phosphate limitation at $D=0.2 \mathrm{~h}^{-1}$ and then the inflowing medium was changed to effect magnesium limitation. Samples were collected $(a) 1 \mathrm{~h}$, $(b, c) 2.5 \mathrm{~h},(d) 3 \mathrm{~h}$ and $(e) 4 \mathrm{~h}$ after changeover. The bacteria were fixed, stained and examined by electron microscopy as previously described (Merad et al., 1989). Bar marker, 0.25 $\mu \mathrm{m}$.

cylindrical wall and pole. In this transition the newly synthesized wall material contains TU and so stains less densely than the old wall, which contains TA. Walls of magnesium-limited bacteria showed uniform dense staining (Fig. 4a). Following transition, less dense material appeared simultaneously at the inner surface of polar and cylindrical wall (Fig. $4 b, c$ ). The layer was almost as thick at the inner surface of polar wall as at cylindrical wall and there was no indication of graded incorporation of new material into the poles from the junction with cylinder nor was there any evidence that new cylindrical wall layers were attached to older polar wall layers. However, old wall material was removed more slowly from the outer surface of the pole (Fig. $4 d, e, f$ ).

These observations suggest that the introduction of new wall into old cell poles may occur by two distinct processes: spreading from the cylinder and inside-to-outside growth. It is possible that these processes operate simultaneously and that the observed differences are a consequence of the particular conditions used in the experiments. In the experiments illustrated in Figs 3 and 4 , transitions between magnesium and phosphate limitation were achieved by changing only the concentration of inorganic phosphate in the feed medium; the magnesium concentration remained constant $(0.075 \mathrm{~mm})$. Under these conditions the magnesium- and phosphate-limited cultures have cell densities of $0.6 \mathrm{~g}^{-1}$ and $1 \cdot 1 \mathrm{~g}^{-1}$ respectively (Lang et al., 1982). Transitions between these two limitations will therefore affect the culture density and so will be accompanied by temporary changes in growth rate as well as by changes in the nature of the 
(a)
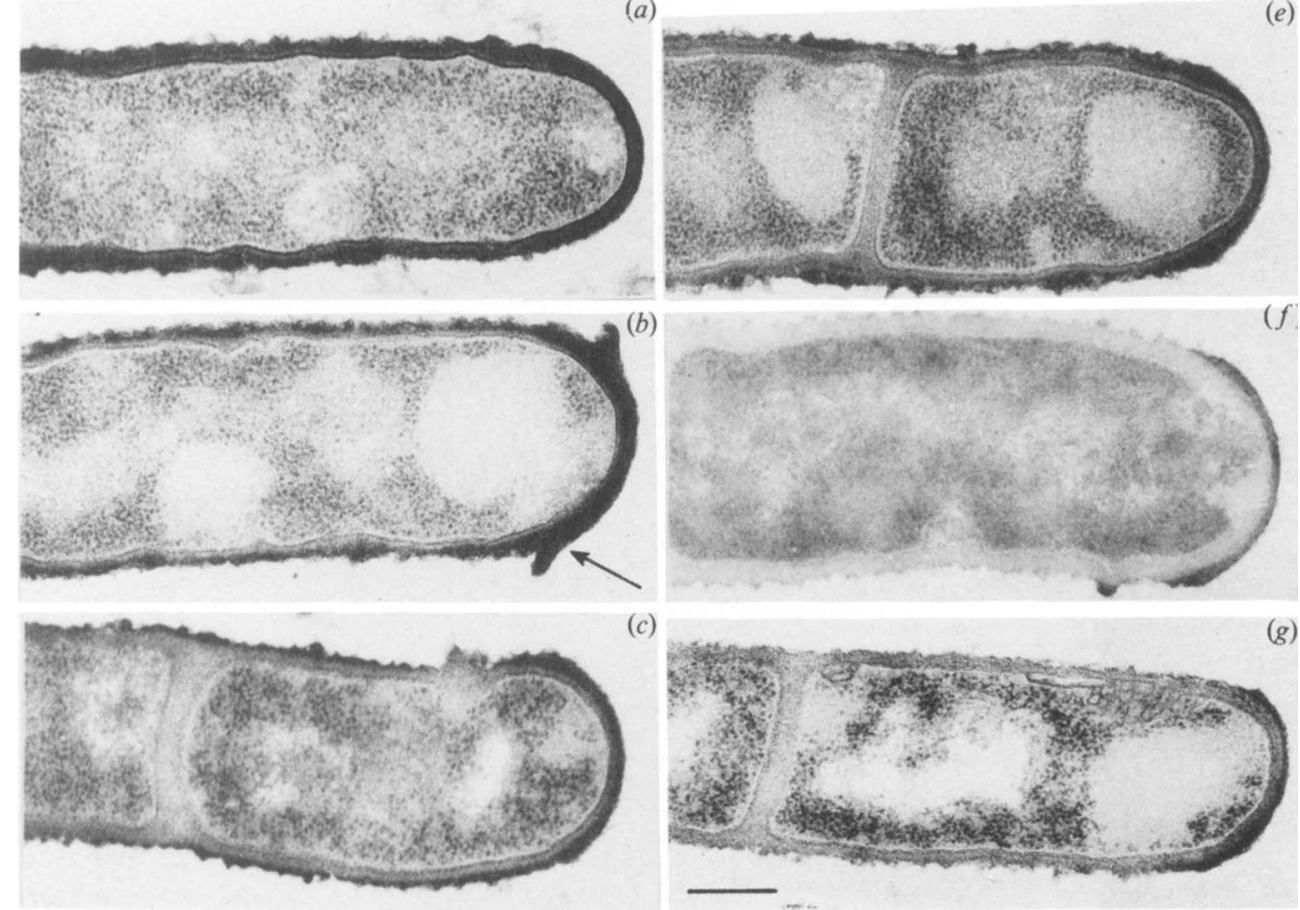

(c)

(g)

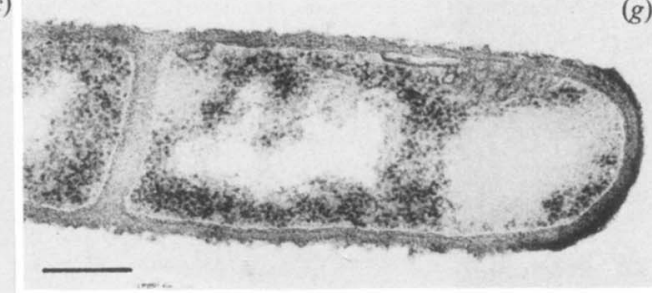

(d)

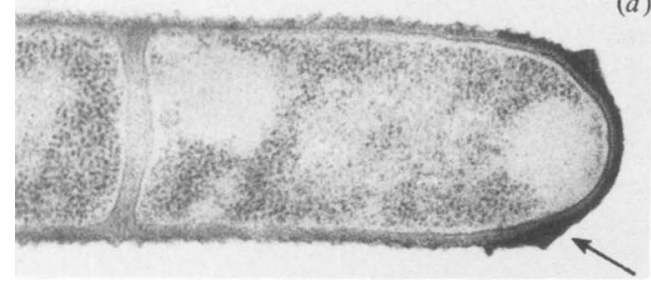

Fig. 4. Deposition of new cell wall material in B. subtilis 168 during transition from magnesium to phosphate limitation. Bacteria were equilibrated under magnesium limitation at a dilution rate of $0 \cdot 2 \mathrm{~h}^{-1}$ and then the inflowing medium was changed to effect phosphate limitation. Samples were collected $(a) 3 \mathrm{~h},(b) 8.5 \mathrm{~h},(c-e) 10 \mathrm{~h},(f) 11.5 \mathrm{~h}$ and $(g) 13 \mathrm{~h}$ after changeover and treated as for Fig. 3 , except for $(f)$ in which the bacteria were stained with $2 \%(w / v)$ uranyl acetate alone. Arrows indicate polar wall bands. Bar marker, $0.25 \mu \mathrm{m}$.

anionic polymer synthesized. Since changeover from magnesium to phosphate limitation results in a decrease in culture density it will be accompanied by a temporary downshift in growth rate; the reverse transition will be accompanied by a temporary upshift in growth rate.

The synthesis of wall and the total amount of wall present in a bacterial cell is affected by growth rate: rapidly growing bacteria contain a lower proportion of wall than those growing more slowly (Ellwood \& Tempest, 1972). A downshift in growth rate would therefore be expected to uncouple wall synthesis and growth in such a way as to increase the relative rate of wall synthesis while an upshift would have the opposite effect. It is possible that the major variation is in the rate of cylindrical wall synthesis so that the ratio of cylindrical to polar wall formation is greater during upshift than downshift. This could explain the different patterns of cell wall incorporation into the poles observed here: during the downshift, associated with the transition from magnesium to phosphate limitation, new material was incorporated into polar and cylindrical wall at essentially the same rate whereas during the upshift, associated with the reverse transition, incorporation into cylindrical wall was faster than into the poles. The possibility that changes in the overall rate of wall synthesis are due primarily to changes in the 


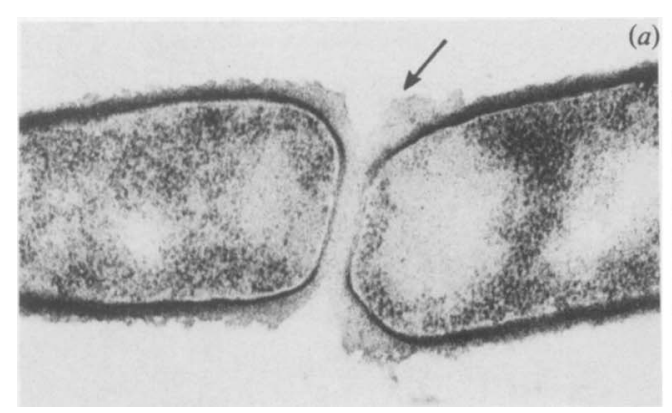

(a)

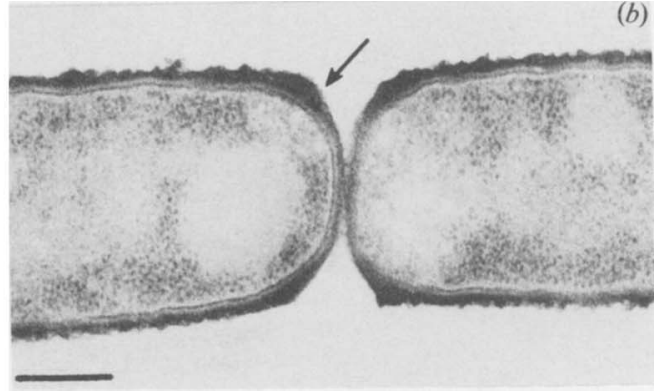

Fig. 5. Septal wall bands in B. subtilis 168 . Transitions between limitations were carried out as in Figs 3 and 4 . Samples shown were collected $(a) 1.5 \mathrm{~h}$ after change to magnesium-limiting medium and $(b) 8.5 \mathrm{~h}$ after change to phosphate-limiting medium. Arrows show septal wall bands.

rate of formation of cylindrical wall, while that of polar wall and perhaps septal wall remains more constant, is compatible with differences in cell size and shape seen at different growth rates (Sargent, 1975).

In the phage-binding experiments with $B$. subtilis W23 illustrated in Figs 1 and 2 the changeover conditions were designed to minimize alterations in growth rate during changeover and the bacterial density remained nearly constant at about $5 \times 10^{9}$ c.f.u. $\mathrm{ml}^{-1}$ (Sturman \& Archibald, 1978). Such changeover experiments do present the danger that growth rate can fluctuate as the concentration of the initially limiting substrate increases while that of the alternative decreases. However, the results of the phage-binding experiments are consistent with those of the electron microscope staining procedure. New phage receptor material incorporated into old poles appears to spread progressively from cylindrical wall towards the tip of the pole in B. subtilis W23 (Fig. 2); new TA incorporated into poles of $B$. subtilis 168 during transition to magnesium limitation may also spread from cylindrical wall and its accessibility to surface probes may decrease towards the polar tip because of diminishing autolytic degradation of the overlying old wall (Fig. 3 c). Phage receptor material remains at the old poles for several generation times after transition of $B$. subtilis W23 to phosphate limitation (Archibald \& Coapes, 1976); densely staining wall material is present at the polar caps of B. subtilis $16813 \mathrm{~h}$ after changeover (Fig. $4 \mathrm{~g}$ ) from magnesium to phosphate limitation.

The raised wall bands marking the sites of septal cleavage noted in $B$. subtilis by Burdett \& Higgins (1978) were seen particularly clearly (Fig. $5 a, b$ ) in the present study because of the contrast in staining between old and new wall in bacteria undergoing transition between the different growth limitations. The staining contrast obtained in the present study shows that the bands are retained at the old poles (Figs $3 d, e$ and $4 d, e$ ). The bands remain visible even when most of the other wall material of the same staining density has been removed from both the cylindrical wall surface and from the rest of the pole (Fig. 4e). They appear to mark the junction of polar and cylindrical wall. Their persistence shows that they are more resistant to turnover than the rest of the wall and it could be that this reflects a structurai difference in the wall at this junction.

Images such as that in Fig. $3(d)$, which show a clear difference in composition between the polar cap and the cylindrical wall, must reflect differences in the rates of incorporation into the two regions of wall. The junction between these two regions must link wall material of different ages and the difference in age will increase with time. This can happen only as a consequence of a rearrangement of peptidoglycan cross-linking in which existing linkages are broken and material in the pole becomes linked to newer cylindrical wall (Fig. 6). Breakage and rearrangement of cross-linkages in peptidoglycan has been demonstrated in biochemical studies in Escherichia coli (Burman \& Park, 1983; Goodell \& Schwarz, 1983) though not yet in Grampositive bacteria. In $B$. subtilis, rearrangement of peptidoglycan cross-linkages may not be confined to the junction of pole and cylindrical wall but could be involved in processes of cylindrical extension in addition to, or instead of, the 'cutting' mechanism proposed by Koch (1983). 


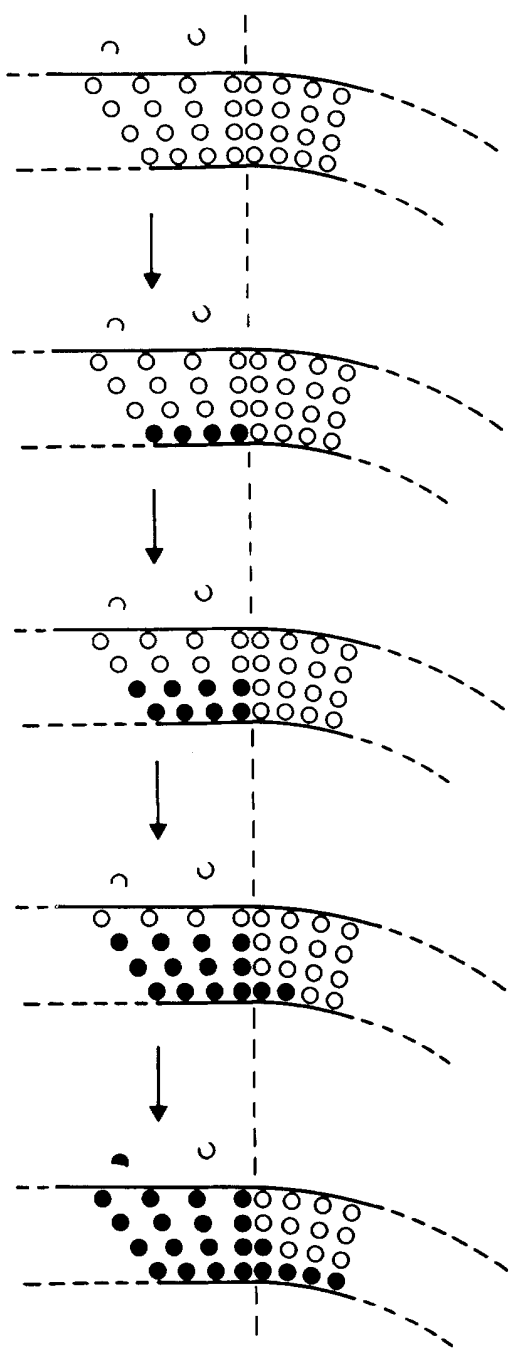

Fig. 6. Diagrammatic representation of the time-course of incorporation of material at the pole/cylinder junction in bacteria having a high relative rate of cylindrical wall synthesis. $\bigcirc$, TU wall; , TA wall. The dotted line shows the junction between the polar and the cylindrical wall.

This work was partly funded by the Medical Research Council. T. M. is in receipt of a Studentship from the Algerian Ministry of Education. We acknowledge the excellent technical assistance of Kevin Glassey and Clive Mellstrom.

\section{REFERENCES}

Anderson, A. J., Green, R. S., Sturman, A. J. \& ARCHibald, A. R. (1978). Cell wall assembly in Bacillus subtilis: location of wall material incorporated during pulsed release of phosphate limitation, its accessibility to bacteriophages and concanavalin A and its susceptibility to turnover. Journal of Bacteriology 136, 886-899.

ARCHIBALD, A. R. (1976). Cell wall assembly in Bacillus subtilis: development of bacteriophage binding pro- perties as a result of the pulsed incorporation of teichoic acid. Journal of Bacteriology 127, 956-960.

ARCHIBALD, A. R. \& CoAPES, H. E. (1976). Bacteriophage SP50 as a marker for cell wall growth in Bacillus subtilis. Journal of Bacteriology 125, 11951206.

BurdetT, I. D. J. \& Higgins, M. L. (1978). Study of pole assembly in Bacillus subtilis by computer reconstruction of septal growth zones seen in central 
longitudinal sections of cells. Journal of Bacteriology 133, 959-971.

Burman, L. G. \& PARK, J. T. (1983). Evidence for multi-site growth of Escherichia coli murein involving concomitant endopeptidase and transpeptidase activity. Journal of Bacteriology 156, 386-392.

Chung, K. L., Hawirko, R. Z. \& IsaAC, P. K. (1964). Cell wall replication. 1. Cell wall growth of Bacillus cereus and Bacillus megaterium. Canadian Journal of Microbiology 10, 43-48.

Clarke-Sturman, A. J. \& Archibald, A. R. (1982). Cell wall turnover in phosphate and potassium limited cultures of Bacillus subtilis W23. Archives of Microbiology 131, 375-379.

Doyle, R. J., Mobley, H. L. T., Joliffe, L. K. \& STREIPS, U. N. (1980). Restricted turnover of the cell wall in Bacillus subtilis. Current Microbiology 5, 1922.

Ellwood, D. C. \& Tempest, D. W. (1972). Effect of environment on bacterial wall content and composition. Advances in Microbial Physiology 7, 83-117.

Fan, D. P. \& Beckman, B. E. (1973). Structural difference between walls from hemispherical caps and partial septa of Bacillus subtilis. Journal of Bacteriology 114, 790-797.

Fan, D. P., Beckman, B. E. \& Beckman, M. M. (1974). Cell wall turnover at the hemispherical caps of Bacillus subtilis. Journal of Bacteriology 117, 13301334.

Fan, D. P., Beckman, B. E. \& Gardner-Eckstrom, H. L. (1975). Mode of cell wall synthesis in Grampositive bacteria. Journal of Bacteriology 123, 1157 . 1162.

Goodell, E. W. \& Schwarz, U. (1983). Cleavage and resynthesis of peptide cross-bridges in Escherichia coli murein. Journal of Bacteriology 156, 136-140.
Hughes, R. C. \& STOKEs, E. (1971). Cell wall growth in Bacillus licheniformis followed by immunofluorescence with mucopeptide-specific antiserum. Journal of Bacteriology 106, 694-696.

Kirchner, G., Koch, A. L. \& Doyle, R. J. (1984). Energised membrane regulates cell pole formation in Bacillus subtilis. FEMS Microbiology Letters 24, 143147.

$\mathrm{KocH}$, A. L. (1983). The surface stress theory of microbial morphogenesis. Advances in Microbial Physiology 24, 301-366.

Koch, A. L. \& DoYle, R. J. (1986). Growth strategy for the Gram-positive rod. FEMS Microbiology Reviews 32, 247-254.

Lang, W. K., Glassey, K. \& Archibald, A. R. (1982). Influence of phosphate supply on teichoic acid and teichuronic acid content of Bacillus subtilis cell walls. Journal of Bacteriology 151, 367-375.

Merad, T., ARChibald, A. R., Hancock, I. C., HaRwood, C. R. \& Hobot, J. A. (1989). Cell wall assembly in Bacillus subtilis: visualization of old and new wall material by electron microscopic examination of samples stained selectively for teichoic acid and teichuronic acid. Journal of General Microbiology 135, 645-655.

Mobley, H. L. T., КосH, A. L., Doyle, R. J. \& STreips, U. N. (1984). Insertion and fate of the cell wall in Bacillus subtilis. Journal of Bacteriology 158, 169-179.

Sargent, M. G. (1975). Control of cell length in Bacillus subtilis. Journal of Bacteriology 123, 7-19.

Sturman, A. J. \& ARChibald, A. R. (1978). Conservation of phage receptor material at the polar caps of Bacillus subtilis W23. FEMS Microbiology Letters 4, 255-259. 